\title{
LOCAL E EXTENSÃO DA DIGESTÃO EM TERNEIROS DESMAMADOS ALIMENTADOS “AD LIBITUM” COM DIETAS RICAS EM CONCENTRADO CONTENDO DIFERENTES FONTES DE PROTEÍNA SUPLEMENTAR ${ }^{1}$
}

\author{
SITE AND EXTENT OF DIGESTION BY WEANED CALVES FED "AD LIBITUM" ON HIGH \\ CONCENTRATE-RICH DIETS WITH DIFFERENT SUPPLEMENTAL PROTEIN SOURCES
}

\author{
Gilberto Vilmar Kozloski ${ }^{2}$ Maria de Lourdes Santorio Ciocca ${ }^{3}$ \\ Luis Maria Bonnecarrère Sanchez ${ }^{4}$ João Batista Teixeira da Rocha ${ }^{5}$
}

RESUMO

\begin{abstract}
Foram utilizados nove terneiros da raça Holandesa $(139 \pm 2,4 \mathrm{~kg})$, fistulados no duodeno, em um delineamento experimental completamente casualizado para estudar o efeito da suplementação com diferentes fontes protéicas $(2 \%$ de uréia ou $10 \%$ de farinha de carne na dieta total) de dietas ricas em concentrado (milho e farelo de soja) sobre o local e extensão da digestão do alimento, em condições de consumo ad libitum. A relação volumoso:concentrado das dietas foi de 30:70. A digestibilidade ruminal e total da matéria seca, matéria orgânica e nitrogênio, assim como o fluxo duodenal de nitrogênio microbiano e residual do alimento, e a eficiência da síntese protéica microbiana foram semelhantes nos dois tratamentos $(P>0,10)$. A digestibilidade ruminal do amido também foi semelhante, mas a digestibilidade total foi menor no tratamento com uréia $(P<0,10)$. No entanto, é provável que isso seja devido mais a limitações dos ruminantes em digerir amido no intestino delgado do que a uma influência do suplemento protéico. $O$ uso de uréia ou de farinha de carne, como fontes de proteína suplementar de dietas à base de milho e farelo de soja, balanceadas para suprir a demanda de crescimento de terneiros jovens e fornecidas ad libitum, não influencia significativamente o processo de digestão nestes animais. Deste modo, a escolha por um outro suplemento depende mais de outros critérios do que dos nutricionais.
\end{abstract}

Palavras-chave: consumo, digestibilidade, farinha de carne, síntese proteica bacteriana, uréia.

\section{SUMMARY}

Nine weaned Holstein calves $(139 \pm 2.4 \mathrm{~kg})$ fitted with duodenal cannulas were used in a completly ramdomized design to study the effects of supplemental protein sources (2\% of

\begin{abstract}
urea or 10\% of meat meal) of high concentrate diets (corn and soybean meal) on site and extent of digestion of feed, in ad libitum feeding conditions. The forage:concentrate ratio was 30:70. The ruminal and total digestibility of dry matter, organic matter and nitrogen, as well as microbial and feed residual nitrogen duodenal flow, and the microbial protein synthesis efficiency were similar for both treatments $(P>0.10)$. The ruminal digestibility of starch was also similar, but total digestibility was lower for urea treatment $(P<0.10)$. However, this is probably due more to the limited capacity of ruminants to digest starch in the intestines than to an effect of the protein supplement. The use of urea or meat meal, as supplemental protein sources for corn and soybean meal based diets, formulated to supply the growth requirements of calves fed ad libitum, did not affect the digestion process.Thus, the choise of the protein supplement do not depend on nutritionals reasons.
\end{abstract}

Key words: bacterial protein synthesis, digestibility, intake, meat meal, urea.

\section{INTRODUÇÃO}

O processo digestivo dos ruminantes é influenciado por uma série de fatores, entre eles a proporção de nitrogênio degradável da dieta necessário para a atividade microbiana e o nível de consumo de alimento. Os microorganismos do rúmen fermentam a matéria orgânica do alimento produzindo ácidos graxos voláteis, amônia e seus próprios componentes celulares, entre outros. Variações no consumo e disponibilidade de substratos, tais como

\footnotetext{
${ }^{1}$ Extraído da Dissertação de Mestrado em Zootecnia do primeiro autor, apresentada na Universidade Federal de Santa Maria (UFSM), com apoio financeiro da FAPERGS.

${ }^{2}$ Aluno do Curso de Pós-graduação em Zootecnia, Universidade Federal do Rio Grande do Sul (UFRGS).

${ }^{3}$ Departamento de Zootecnia, UFRGS.

${ }^{4}$ Departamento de Zootecnia, Centro de Ciências Rurais, UFSM, Campus, Camobi, 97105-900, Santa Maria, RS, Brasil. E-mail: bonne@ccr.ufsm.br.

${ }^{5}$ Departamento de Química, UFSM. 
nitrogênio para os microorganismos, podem alterar o padrão de fermentação e a extensão da digestão da matéria orgânica no rúmen, com conseqüente mudanças no fluxo de componentes do alimento e de microorganismos para o intestino delgado (RUSSEL et al., 1992).

Proteína microbiana pode representar uma importante proporção da proteína que alcança o intestino delgado. Contudo, sua síntese no rúmen é insuficiente para suportar altas taxas de crescimento de bovinos jovens (ØRSKOV, 1977). Para suprir a demanda de uma maior produção, parte da proteína da dieta deve escapar da degradação ruminal e estar disponível para digestão e absorção no intestino delgado. De um lado, procura-se incrementar o fluxo de aminoácidos de alto valor biológico para o intestino, pela utilização de fontes de proteína de baixa solubilidade ruminal, em quantidades que não limitem o crescimento microbiano. Por outro lado, busca-se também otimizar a utilização de fontes de nitrogênio não protéico na dieta de ruminantes. Farinha de carne, cuja solubilidade ruminal é baixa e, uréia, a qual é altamente solúvel, são suplementos protéicos de uso potencial na alimentação de ruminantes. Em um estudo de digestão com terneiros recebendo dietas à base de cevada e suplementadas com farinha de carne e/ou uréia, LEIBHOLZ (1980) observou que a síntese de proteína microbiana em relação à matéria orgânica fermentada no rúmen foi similar entre os tratamentos, mas o fluxo e a absorção de aminoácidos no intestino delgado foram mais altos para as dietas contendo farinha de carne. Contudo, em estudos de desempenho de terneiros desmamados precocemente, quando uréia ou farinha de carne foram adicionadas para elevar de 12 para $18 \%$ o teor de proteína bruta da dieta basal, os resultados de consumo, ganho de peso e eficiência da utilização do alimento foram variáveis (LEIBHOLZ \& NAYLOR，1971; LEIBHOLZ \& KANG，1973; KOZLOSKI et al., 1996).

Normalmente, experimentos de digestibilidade são conduzidos com consumo restrito pelos animais. Nestas condições, embora se considere que a variável consumo não influencia os resultados, eles podem ser diferentes daqueles obtidos em condições normais de alimentação, pois é provável a existência de interações entre consumo e digestibilidade do alimento.

O objetivo do presente trabalho foi verificar o local e a extensão da digestão de dietas ricas em concentrado, suplementadas com uréia ou farinha de carne, em terneiros desmamados precocemente, sob condição de consumo ad libitum.

\section{MATERIAL E MÉTODOS}

O estudo foi conduzido com nove terneiros machos castrados da raça Holandesa, com peso vivo médio de $139+2,4 \mathrm{~kg}$, canulados no duodeno e distribuídos aleatoriamente em dois tratamentos: feno + concentrado com uréia (U), e feno + concentrado com farinha de carne (FC). A formulação e composição das dietas estão presentes na tabela 1 .

Após recuperação da cirurgia de canulação duodenal, os dados foram obtidos durante oito dias. Neste período, o alimento era pesado e oferecido duas vezes ao dia, com um excesso contínuo de aproximadamente $10 \%$. O feno era triturado e misturado com o concentrado no cocho. Os animais tinham livre acesso à agua. Óxido de cromo $\left(\mathrm{Cr}_{2} \mathrm{O}_{3}, 5\right.$ g/dia) foi embrulhado em papel jornal dividido em duas porções diárias de 2,5 g cada, e fornecido aos animais pela manhã e pela tarde logo antes do alimento, durante os oito dias, como um indicador externo de fluxo de matéria seca pelo trato digestivo. $\mathrm{O}$ produto era introduzido diretamente na cavidade bucal dos animais, na base da língua. Durante alguns minutos, os animais eram observados para verificar a eficiência do procedimento.

Amostras de alimento, sobras, digesta duodenal e fezes foram coletadas no $6^{\circ}, 7^{\circ}$ e $8^{\circ}$ dias após o início do oferecimento do $\mathrm{Cr}_{2} \mathrm{O}_{3}$. Amostras

\begin{tabular}{|c|c|c|}
\hline ITEM & URÉIA (U) & $\begin{array}{l}\text { FARINHA DE } \\
\text { CARNE (FC) }\end{array}$ \\
\hline \multicolumn{3}{|l|}{ Formulação (kg): } \\
\hline Feno $^{2}$ & 30 & 30 \\
\hline Milho (grão quebrado) & 56 & 43 \\
\hline Farelo de soja & 10 & 15 \\
\hline Farinha de carne & - & 10 \\
\hline Uréia $^{3}$ & 2 & - \\
\hline $\begin{array}{l}\text { Premix Vitamin-mineral } \\
\text { Composição }(\%) \text { : }\end{array}$ & 2 & 2 \\
\hline Matéria seca & 82,3 & 83,0 \\
\hline Matéria orgânica ${ }^{4}$ & 95,4 & 91,7 \\
\hline Nitrogênio ${ }^{4}$ & 2,9 & 2,8 \\
\hline Amido $^{4}$ & 38,7 & 27,8 \\
\hline
\end{tabular}

${ }^{1}$ Dietas formuladas para conter $12 \%$ de proteína bruta na dieta basal e elevada para $18 \%$ pela adição de uréia ou farinha de carne (LEIBHOLZ \& KANG, 1973).

Capim papuã (Brachiaria plantaginea) com 50 dias de crescimento e $5 \%$ de proteína bruta.

Uréia + sulfato de amônia na proporção de 9:1.

$\%$ na matéria seca. 
de alimentos e sobras foram compostas por animal, secas a $55^{\circ} \mathrm{C}$ por 2 a 3 dias, moídas e estocadas para posterior análise. Amostras de digesta duodenal $( \pm 70$ $\mathrm{ml})$ e fezes $( \pm 50 \mathrm{ml})$ foram coletadas simultaneamente a intervalos de 6 horas, durante o mesmo período de três dias, mantidas em gelo durante a coleta e, posteriormente, armazenadas em congelador $\left( \pm-20^{\circ} \mathrm{C}\right)$. Após, foram secas a $55^{\circ} \mathrm{C}$ por 5 a 7 dias, moídas e armazenadas (as amostras de digesta duodenal no congelador) para posterior análise. Para análise, essas amostras também foram compostas por animal, com exceção daquelas utilizadas para determinação do indicador de produção microbiana, que foram compostas por tratamento.

Os alimentos, sobras, digesta duodenal e fezes foram analisados para o seu conteúdo de matéria seca (MS), matéria orgânica (MO) e nitrogênio (N) total de acordo com as recomendações da AOAC (1984). Foi determinado também o conteúdo de nitrogênio amoniacal $\left(\mathrm{N}-\mathrm{NH}_{3}\right)$ nas amostras úmidas de digesta duodenal. Para tanto, elas foram centrifugadas a $1000 \mathrm{x}$ g por 15 ', e $3 \mathrm{ml}$ do sobrenadante, 7,5ml de uma solução de hidróxido de potássio $2 \mathrm{~N}$ e $9,5 \mathrm{ml}$ de água destilada foram adicionados em um tubo de micro-Kjeldahl. A mistura foi destilada em um equipamento do tipo micro-Kjeldahl em um frasco de Erlenmeyer, contendo 7,5ml de uma solução de ácido bórico a $4 \%$ e indicador verde de bromocresol e vermelho de metila e, a seguir, titulado com solução de ácido sulfúrico $0,05 \mathrm{~N}$. O conteúdo de $\mathrm{N}-\mathrm{NH}_{3}$ foi somado como matéria seca da amostra de digesta duodenal. Ácido diaminopimélico (DAPA) foi analisado nas amostras secas de digesta duodenal, as quais foram lavadas sucessivamente com soluções de ácido tricloroacético, etanol, clorofórmio e éter (McALLAN \& SMITH, 1969) e então hidrolisadas com $\mathrm{HCl}$ 6N, filtradas e secas (EL-SHAZLY \& HUNGATE, 1966). O DAPA foi isolado cromatograficamente (SMITH et al., 1978) e determinado colorimetricamente pelo método descrito por EL-SHAZLY \& HUNGATE (1966). Nitrogênio microbiano $(\mathrm{Nm})$ foi estimado considerando-se que $0.60 \%$ do $\mathrm{Nm}$ estava no DAPA (Nm $(\mathrm{g} /$ dia $)=\mathrm{g}$ DAPA $/ \mathrm{g}$ matéria seca de digesta duodenal x 24,5 x fluxo de matéria seca duodenal (g/dia)). Esta relação foi definida com base nas revisões de SILVA \& LEÃO (1979) and SIDDONS $\boldsymbol{e t} \boldsymbol{a l}$. (1982). $\mathrm{Cr}_{2} \mathrm{O}_{3}$ foi determinado nas amostras de alimentos, de digesta duodenal e fezes. As amostras foram digeridas pelo método de CZARNOCKI $\boldsymbol{e t}$ al. (1961) e cromo foi determinado por espectofotometria de absorção atômica. O conteúdo de amido nas amostras de alimento, digesta duodenal e fezes foi determinado enzimaticamente pelo método de KARTCHNER \& THEURER (1981).

O fluxo de MS duodenal e fecal foi estimado como segue:

MS duodenal ou fecal $(\mathrm{g} / 24 \mathrm{~h})=\mathrm{mg} \mathrm{Cr} / \mathrm{g}$ MS consumida $\mathrm{x}$ MS consumida (g/24 h) / mg Cr/g MS duodenal ou fecal

Os dados foram submetidos à análise de variância, considerando-se o consumo de matéria seca como uma covariável para os dados de digestão. $\mathrm{O}$ modelo matemático foi o seguinte: $\mathrm{Y}_{\mathrm{ij}}=\mu+$ $\mathrm{T}_{\mathrm{i}}+\mathrm{CMS}_{\mathrm{kij}}+\mathrm{e}_{\mathrm{ij}}$, onde $\mathrm{Y}_{\mathrm{ij}}=$ variável observada; $\mu=$ média geral; $\mathrm{T}_{\mathrm{i}}=$ efeito dos tratamentos; $\mathrm{CMS}_{\mathrm{kij}}=$ coeficiente de regressão entre o consumo de matéria seca e as variáveis observadas e $\mathrm{e}_{\mathrm{ij}}=$ erro experimental associado a cada observação. As médias foram ajustadas para o efeito da covariável. Foram utilizados os procedimentos do "software" SAS (1990), os quais foram GLM para análise de variância e LSMEANS para obtenção das médias. As comparações foram consideradas significativamente diferentes quando a probabilidade do erro tipo 1 foi menor ou igual a 0,10 .

\section{RESULTADOS E DISCUSSÃO}

As médias de peso vivo e de consumo dos componentes do alimento são apresentados na tabela 2. Os resultados são médias de 5 animais no tratamento com uréia e 4 animais no com farinha de carne. O fluxo duodenal e a produção fecal, bem como a digestibilidade ruminal e total da MS, MO e do amido estão sumarizados na tabela 3 . Os resultados de digestão dos compostos nitrogenados são apresentados na tabela 4. Com exceção da produção fecal e da digestibilidade total do amido, nenhuma

Tabela 2 - Peso vivo médio (PV) dos terneiros e consumo dos componentes das dietas experimentais.

\begin{tabular}{lcccc}
\hline ITEM & $\mathrm{U}$ & $\mathrm{FC}$ & $\mathrm{EP}^{1}$ & $\mathrm{CV}^{2}$ \\
\hline & 138 & 140 & 7 & 5 \\
PV(kg) & & & & \\
Consumo (g/dia): & 3916 & 3262 & 452 & 12 \\
Matéria seca & 3712 & 2926 & 410 & 11 \\
Matéria orgânica & 114 & 90 & 14 & 13 \\
Nitrogênio & 1364 & 816 & 121 & 10 \\
Amido & & & & \\
\hline
\end{tabular}

${ }^{1}$ Erro padrão das médias onde $\mathrm{n}=5$ no tratamento com uréia e $\mathrm{n}=4$ no tratamento com farinha de carne.

${ }^{2}$ Coeficiente de variação (\%). 
Tabela 3 - Fluxo duodenal, produção fecal e digestibilidade dos componentes das dietas experimentais ${ }^{1}$

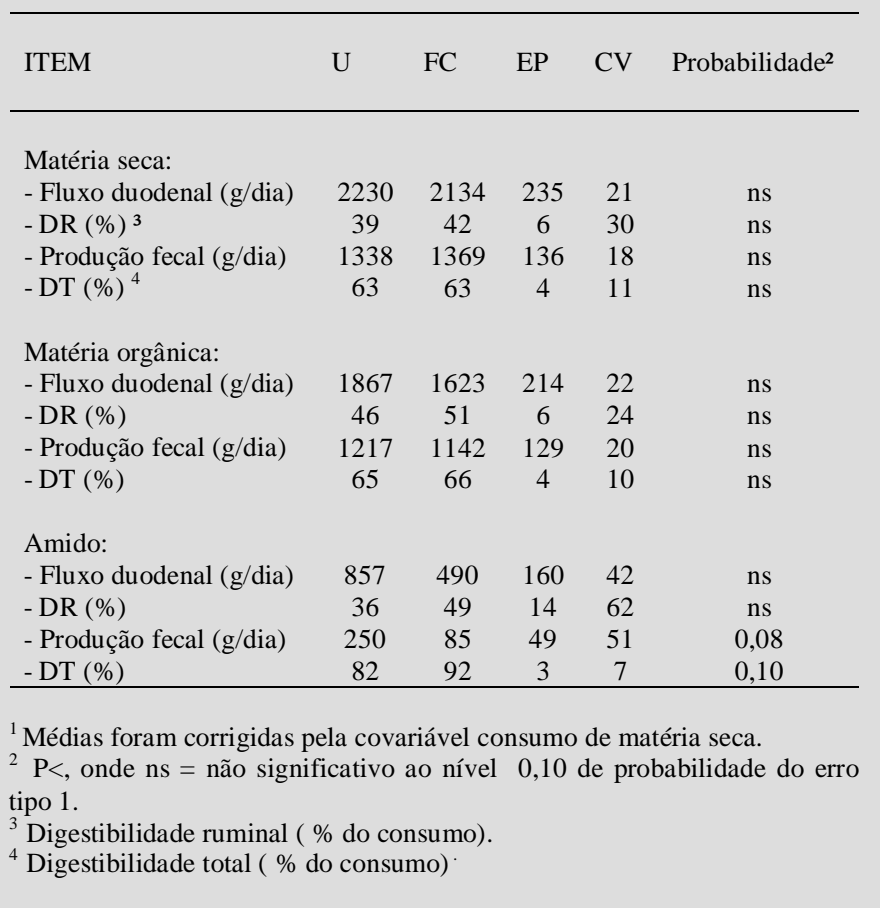

Tabela 4 - Digestão dos compostos nitrogenados¹.

\begin{tabular}{|c|c|c|c|c|c|}
\hline ITEM & $\mathrm{U}$ & $\mathrm{FC}$ & EP & $\mathrm{CV}$ & Probabilidade \\
\hline Nitrogênio total: & 83 & 69 & 7 & 16 & ns \\
\hline - Fluxo duodenal (g/dia) & 22 & 33 & 7 & 48 & $\mathrm{~ns}$ \\
\hline$-\mathrm{DR}(\%)^{2}$ & 33 & 33 & 7 & 14 & $\mathrm{~ns}$ \\
\hline - Fecal (g/dia) & 68 & 67 & 3 & 8 & $\mathrm{~ns}$ \\
\hline \multicolumn{6}{|l|}{$-\mathrm{DT}(\%)^{3}$} \\
\hline $\begin{array}{l}\text { Fluxo duodenal: } \\
\mathrm{N}-\mathrm{NH}_{3}(\mathrm{~g} / \mathrm{dia})\end{array}$ & 4,8 & 6,1 & 1,3 & 46 & ns \\
\hline $\mathrm{Nm}(\mathrm{g} / \mathrm{dia})^{4}$ & 45,5 & 35,8 & 4,5 & 20 & ns \\
\hline $\operatorname{MOADR}(\mathrm{kg} / \mathrm{dia})^{5}$ & 1,58 & 1,63 & 0,21 & 24 & ns \\
\hline $\mathrm{g} \mathrm{Nm} / \mathrm{kg}$ MOADR & 31,2 & 22,1 & 5,9 & 40 & ns \\
\hline $\mathrm{N}$ residual do alimento ${ }^{6}$ & 0,27 & 0,22 & 0,04 & 30 & $\mathrm{~ns}$ \\
\hline
\end{tabular}

${ }^{1}$ Médias foram ajustadas pela covariável consumo de matéria seca.

${ }^{2}$ Digestibilidade ruminal (\% do consumo).

${ }^{3}$ Digestibilidade total ( $\%$ do consumo).

${ }^{4} \mathrm{~g}$ DAPA/ $\mathrm{g}$ de matéria seca de digesta duodenal $\times 24,5$ x fluxo de matéria seca duodenal (g/dia).

${ }^{5}$ Matéria orgânica aparentemente digerida no rúmen.

${ }^{6}$ Relação $\mathrm{N}$ do alimento não degradado no rúmen / $\mathrm{N}$ consumido.

[ $\mathrm{N}$ do alimento não degradado no rúmen= $\mathrm{N}$ duodenal total $-\left(\mathrm{N}_{-} \mathrm{NH}_{3}+\right.$ $\mathrm{Nm})$ ] outra variável associada ao processo de digestão foi influenciada significativamente pelos tratamentos $(\mathrm{P}>0,10)$.

Os resultados de digestibilidade ruminal e total dos componentes do alimento, obtidos no presente estudo, foram menores que os obtidos em outros estudos semelhantes, com terneiros consumindo dietas ricas em grãos (LEIBHOLZ \& NAYLOR, 1971; LEIBHOLZ \& KANG, 1973; SMITH et al., 1978; VEIRA et al., 1980), os quais geralmente são caracterizados por utilizarem níveis restritos de consumo de alimento. No presente estudo, o consumo de matéria seca foi relativamente alto (em média $2,6 \%$ do peso vivo) e as dietas continham altas proporções de grão de milho. $\mathrm{O}$ incremento do consumo, particularmente de dietas contendo altas proporções de milho (não processado pelo calor) tendem a reduzir a digestão da matéria orgânica, principalmente no retículo-rúmen (GALYEAN et al., 1979; ROBINSON et al., 1985; FIRKINS et al., 1986; SNIFFEN et al., 1992).

Embora a digestibilidade ruminal tenha sido semelhante, a digestibilidade total do amido foi mais alta no tratamento com farinha de carne. No entanto, é mais provável que isso esteja associado à menor quantidade de amido que chegou ao intestino neste tratamento do que a uma influência do suplemento protéico. Estudos têm demonstrado que a digestão de amido natural de milho infundido no intestino delgado é limitada ( KREIKEMEIER et al., 1991; KREIKEMEIER \& HARMON, 1995).

Normalmente, suplementos protéicos de baixa solubilidade ruminal são associados com menor digestibilidade ruminal do nitrogênio e da matéria seca (LEIBHOLZ, 1980; AMOS, 1986; HOOVER \& STOKES, 1991). Deste modo, era esperado que a digestibilidade ruminal do nitrogênio na dieta contendo uréia fosse mais alta, pois sua degradação no rúmen é mais rápida e intensa que a farinha de carne (BRODERICK \& WALLACE,1988). Esse fenômeno poderia causar uma maior perda de nitrogênio por absorção de amônia e, conseqüientemente, aumentaria o desaparecimento de nitrogênio nos pré-estômagos, como reportado por LEIBHOLZ (1980). Da mesma forma, o nitrogênio residual do alimento, não degradado no rúmen e que fluiu para o duodeno, foi similar nos dois tratamentos, embora fosse esperado 
ser mais alto para a dieta contendo farinha de carne. Com vistas a balancear a relação volumoso:concentrado e conteúdo de nitrogênio, inevitavelmente as dietas também variaram na proporção de milho e de farelo de soja, além do suplemento protéico. Considerando que, por um lado, a proteína do farelo de soja é predominantemente solúvel e, por outro, a do milho é pouco solúvel e resistente à degradação ruminal (LUDDEN \& CECAVA, 1995), o fluxo total de nitrogênio para o duodeno pode ter sido significativamente influenciado por estes dois componentes da dieta, anulando, de certa forma, as diferenças entre uréia e farinha de carne relativo à digestão ruminal do nitrogênio.

A eficiência da síntese protéica microbiana (tabela 4) também foi semelhante nas duas dietas, sendo que os valores estão entre aqueles normalmente encontrados em vários outros estudos (SMITH, 1975; STERN \& HOOVER,1979). É provável que a dieta basal tenha suprido a demanda bacteriana por nitrogênio para máximo crescimento e/ou fermentação da matéria orgânica no rúmen (aproximadamente 12 a $13 \%$ de proteína bruta na matéria seca da dieta basal). Da mesma forma, VEIRA et al. (1980) alimentou terneiros com uma dieta basal de farelo de soja e milho e observou que um incremento gradual de proteína bruta na dieta de 10 até $16 \%$ pela adição de farelo de soja não modificou o fluxo de nitrogênio microbiano para o intestino delgado. O rendimento microbiano também é considerado ser influenciado pela digestão dos carboidratos no rúmen (RUSSEL $\boldsymbol{e t}$ al., 1992). No presente trabalho, a digestão ruminal da matéria orgânica e do amido foi semelhante nos dois tratamentos, o que é coerente, então, com os resultados de rendimento microbiano obtidos.

\section{CONCLUSÕES}

O uso de uréia ou de farinha de carne como fonte de proteína suplementar em dietas à base de milho e farelo de soja não interfere no processo de digestão de terneiros em crescimento, alimentados ad libitum. Deste modo, a escolha da fonte protéica dependerá mais de outros critérios do que dos nutricionais.

\section{REFERÊNCIAS BIBLIOGRÁFICAS}

AMOS, H.E. Influence of dietary protein degradability and energy concentration on growth of heifers and steers and intraruminal protein metabolism. Journal of Dairy Science, v. 69 , p. $2099-2110,1986$.

ASSOCIATION OF OFFICIAL ANALYTICAL CHEMISTS. Official methods of analysis. 12. ed. Washington, D.C., 1984, $1141 \mathrm{p}$.
BRODERICK, G.A., WALLACE, R.J. Effects of dietary nitrogen source on concentrations of ammonia, free amino acids and fluorescamine - reactive peptides in the sheep rumen. Journal of Animal Science, v. 66, p. 2233-2238, 1988.

CZARNOCKI, J., SIBBALD, I.R. EVANS, E.V. The determination of chromium oxide in samples of feed and excreta by acid digestion and spectrophotometry. Canadian Journal of Animal Science, v. 4, p. 167-179, 1961.

EL-SHAZLY, K., HUNGATE, R. Method for measuring diaminopimelic acid in total rumen contents and its application to the estimation of bacterial growth. Applied Microbiology, v. 14, p. 27-30, 1966.

FIRKINS, J.L., BERGER, L.L., MERCHEN, N.R., et al. . Effects of feed intake and protein degradability on ruminal characteristics and site of digestion in steers. Journal of Dairy Science, v. 69, p. 2111-2123, 1986.

GALYEAN, M.L., WAGNER, D.G., OWENS, F.N. Level of feed intake and site and extent of digestion of high concentrate diets by steers. Journal of Animal Science, v. 49, p. 199-203, 1979.

HOOVER, W.H., STOKES, S.R. Balancing carbohydrates and proteins for optimum rumen microbial yield. Journal of Dairy Science,v. 74, p. 3630-3644, 1991.

KARTCHNER, R.J., THEURER, B. Comparison of hydrolysis methods used in feed, digesta, and fecal starch. Journal of Agricultural and Food Chemistry, v. 29, p. 8-11, 1981.

KOZLOSKI, G.V., SANCHEZ, L.M.B., BOETCHER, A.C. Ganho de peso e consumo de alimento em bezerros suplementados com uréia ou farinha de carne. Pesquisa Agropecuária Brasileira, v. 31, p. 529-532, 1996.

KREIKEMEIER, K.K., HARMON, D.L., BRANDT JR., R.T., et al. Small intestinal starch digestion in steers: effect of various levels of abomasal glucose, corn starch and corn dextrin infusion on small intestinal disappearance and net glucose absorption. Journal of Animal Science, v. 69, p. 328-338, 1991.

KREIKEMEIER, K.K, HARMON, D.L. Abomasal glucose, maize starch and maize dextrin infusions in cattle: smallintestinal disappearance, net portal glucose flux and ileal oligosaccharide flow. British Journal of Nutrition, v. 73, p. 763-772, 1995

LEIBHOLZ, J., NAYLOR, R.W. The effect of urea in the diet of the early-weaned calf on weight gain, nitrogen and sulphur balance, and plasma urea and free amino acid concentrations. Australian Journal of Agricultural Research, v. 22, p. 655662, 1971.

LEIBHOLZ, J., KANG, H.S. The crude protein requeriment of early-weaned calf given urea, meat meal or soya bean meal with or without sulphur supplementation. Animal Production, v. 17, p. 257-265, 1973.

LEIBHOLZ, J. Urea and meat meal in the diets of ruminant calves - the sites of digestion and the nitrogen requeriments for microbial protein synthesis. Australian Journal of Agricultural Research, v. 31, p. 163-177, 1980.

LUDDEN, P.A., CECAVA, M.J. Supplemental protein sources for steers fed corn-based diets: I. Ruminal characteristics and intestinal amino acid flows. Journal of Animal Science, v. 73, p. 1466-1475, 1995. 
McALLAN, A.B., SMITH, R.H. Determination of nucleic acids in digesta. British Journal of Nutrition, v. 23, p. 671- 683, 1969.

ØRSKOV, E.R. Capacity for digestion and effects of composition of absorbed nutrients on animal metabolism. Journal of Animal Science, v. 46, p. 600-608, 1977.

ROBINSON, P.H., SNIFFEN, C.J., VAN SOEST, P. J. Influence of level of feed intake on digestion and bacterial yield in the forestomachs of dairy cattle. Canadian Journal of Animal Science, v. 65, p. 437-444, 1985

RUSSEL, J.B., O'CONNOR, J.D., FOX, D.G., et al.. A net carbohydrate and protein system for evaluating cattle diets: I. Ruminal fermentation. Journal of Animal Science, v. 70, p. $3551-3561,1992$.

SAS INSTITUTE. SAS user's guide: Statistics Version 1990. SAS. Cary, N. C., 1990.

SIDDONS, R.C., BEEVER, D.E., NOLAN, J.V. A comparison of methods for the estimation of microbial nitrogen in duodenal digesta of sheep. British Journal of Nutrition, v. 48, p. 377 $389,1982$.

SILVA, J.F.C., LEÃO, M.I.. Fundamentos de nutrição de ruminantes. Piracicaba: Livroceres, 1979, 380 p.
SMITH, R.H. Nitrogen metabolism in the rumen and the composition and nutritive value of nitrogen compounds entering the duodenum. In: MCDONALD, I.W., WARNER, A.C.I. (Eds). Digestion and metabolism in the ruminant Armidale: The University of New England Publishing Unit, Australia, 1975. p. 399-415.

SMITH, R.H., McALLAN, A.B., HEWITT, D., et al. . Estimation of amounts of microbial and dietary nitrogen compounds entering the duodenum of cattle. Journal of Agricultural Science, v. 90, p. 557-568, 1978.

SNIFFEN, C.J., O'CONNOR, J.D., VAN SOEST, P.J., et al.. A net carbohydrate and protein system for evaluating cattle diets: II. Carbohydrate and protein availability. Journal of Animal Science, v. 70, p. 3562-3577, 1992

STERN, M.D., HOOVER, W.H.. Methods for determining and factors affecting rumen microbial protein synthesis: a review. Journal of Animal Science, v. 49, p. 1590-1603, 1979.

VEIRA, D.M., MACLEOD, G.K, BURTON, J.H., et al. Nutrition of the weaned Holstein calf. I. Effect of dietary protein level on rumen metabolism. Journal of Animal Science, v. 50, p. 937-944, 1980

Ciência Rural, v. 29, n. 2, 1999. 